\title{
Mobile Midwesterners The Impact of Migration on Aging, Health, and Community
}

\author{
Matthew Dalstrom \\ Department of Anthropology and Sociology \\ Rockford College
}

\begin{abstract}
As the population in the US ages, there is increasing need to study aging and its relationship to quality of life, health, and community. Quality of life is closely correlated with belonging to a community. Unfortunately, as seniors age there is a propensity for them to become increasingly isolated as their mobility decreases and their friends and family members die or move away. As a result, some seniors in the Midwest have begun to migrate to RV parks in the Lower Rio Grande Valley ("LRGV") in south Texas that function as temporary retirement communities for the winter. While there, they reconnect with friends and family members and engage in a variety of social, civic, and exercise related activities. Further, they participate in a variety of health seeking behaviors such as health screenings, trading medications, and using the Mexican health care system. This article explores these practices and discusses how Winter Texans choose the LRGV, how new members become integrated into RV parks, and how life in the parks impacts health and access to health care services. It also highlights the impact that seasonal migration has on community formation, health seeking behaviors, and the diversity of retirement communities.
\end{abstract}

Keywords: Winter Texans, health, migration, RV Parks

\section{INTRODUCTION}

The United States is in the midst of a demographic transformation as the number of people over the age of 65 has grown to its highest level, accounting for nearly 13 percent of the total population (Werner 2011). As the population ages, policy makers, families, and retirees themselves all seek to improve the often isolating process of aging that occurs as mobility decreases, friends die, and family members move away. "Aging in Place," as social anthropologist Ann Bookman (2008) refers to it, is a process that occurs as seniors become more removed from their communities as they age, resulting in a variety of health issues such as depression and decreased mobility. The 'aging in place' narrative comes under scrutiny, however, as seniors continue to live longer and healthier lives through access to improved health care, pensions and/or social security insurance. Accompanying this shift is a growing sentiment that retirement should be viewed not as the end of life, but as the reward for a life of working (Bartling 2006). This new mentality has lead to the expansion of retirement communities that cater to the notion that retirement should be fun and leisurely while simultaneously addressing the pragmatic concerns of needing more care as one ages. Retirement communities vary along a cost, care, and amenities continuum, but they all offer the possibility of aging not alone, but in an atmosphere that provides social activities and fosters friendships, which can improve the social and physical aspects of growing older (Bekhet and Zauszniewski 2011). Selecting the right community in the best location can be challenging, especially when it is far from home, family, and friends. Moreover, choosing the wrong place can be detrimental, causing increased stress, (Kao, Travis, and Acton 2004), loneliness, and has been associated with lower self-rated health and depression (Rossen 2007). 
Therefore, the central issues for many seniors are how to counteract the aging in place phenomenon, enjoy their retirement years, mitigate the stress of moving to a retirement community, and still feel connected to their old lives. For those mobile enough, one option is to become a seasonal migrant, blending the benefits of living in their home with those of temporary retirement community living. Seasonal migration, takes many forms but it is distinguished from other types of travel during retirement because migrants repeatedly travel to the same destination community and spend at least one month there. Another characteristic is that the destination usually improves one's lifestyle through climate, social activities, and an expanded support network of friends.

Seasonal migrant communities can consist of a wide variety of retirees, but they are frequently associated with "snowbirds," northern retirees who migrate to the south during the winter. Snowbirds primarily come from Canada or the northern US and frequently end up in RV parks scattered throughout Florida, Arizona and Texas. Unlike other types of retirement communities, residents only stay for one to six months and most are in good health. Parks do not provide year around care or intensive medical support, and people live in RVs. Moreover, retirees are not burdened with the stress of permanently leaving their home or the high costs of living in permanent retirement communities.

For many, the annual movement south marks a drastic shift in lifestyle as home and apartment living is traded for RVs and friends who lived miles away become close neighbors. The parks vary in size ranging from a few hundred residents to several thousand and the close proximity coupled with the small living space "requires you to know your neighbor and be social," one resident explained. It also encourages a strong sense of community and provides seniors with access to exercise clubs, health screenings, social clubs, and tourism activities, just like year-round retirement communities.

While seasonal migrants can choose a variety of locations, approximately 150,000 Midwesterners tend to winter in the southeastern region of Texas known as the Lower Rio Grande Valley (LRGV). ${ }^{1}$ Locally they are not referred to as snowbirds, but "Winter Texans," retirees 55 or older who spend at least one month per year living in Texas. While they consist of a very diverse group from around the northern US and Canada, the majority (52.3 percent) come from the Midwest (Ghaddar and Simpson 2008).
For several decades researchers have explored the seasonal migration of retirees to Florida, Arizona, and to a lesser degree Texas. Primarily the research focus has been on how communities form within the parks (Fry 1979), demographics (Sullivan 1985), social structures and marginality (Van Den Hoonaard and Kestin 2002), and impact on the host community (Ghaddar and Simpson 2008). To a lesser degree, it has explored the relationship people have with their home community (Bjelde and Sanders 2009), the impact that migration has on health (McHugh and Mings 1994; Chui, Cohen and Naumova 2011) and retirees usage of Mexican health care (Dalstrom 2012). However, the Winter Texan community is different from the other seasonal migrants because of their historical connection with LRGV, their emphasis on maintaining ties to the Midwest, and because access to Mexican medical care has had an impact their health and health seeking behaviors.

To understand the relationship between seasonal migration, health, and community formation, this article will draw upon Roger Rouse's (1992) concept of the transmigration circuit. While his work focuses on the migration decisions of Mexican immigrants in the US, his framework for conceptualizing the importance of the connection between the home and destination community is particularly useful. According to Rouse, migration is not random, nor is it isolating, or the sole result of economic conditions, but migrant destinations are chosen based on historic, economic, and social conditionals that create a circuit of sending and receiving communities. While these communities are separated by space, the continued return of migrants to the same location (LRGV) and the perpetual interest in the sending community (the Midwest) maintains bonds that "form a single community spanning across locales" (162). For Winter Texans this circuit orients them both to Texas and their home communities, and creates their "winter family" which consists of friends and family from the sending community along with other people from the Midwest who live together in the LRGV.

This article will explore seasonal migration within the context of the transmigration circuit through a) discussing how Winter Texans choose the LRGV, b) exploring how new members get integrated into the community, and c) discussing how living in the parks impacts health and access to health care services both in the US and Mexico. Through the transmigration circuit social connections between the Midwest and the LRGV are formed and maintained. These close social ties are not only important in choosing a migration destination, but impact health, happiness, and longevity (Bjelde and Sanders 2009). 
Moreover, seasonal migration to the LRGV creates unique health care opportunities for retirees such as exercise classes, health screenings, and in some cases access to the Mexican medical system.

\section{Methods}

Research for this article is part of a larger study on health and medical travel along the US/Mexico border that was conducted over eleven months in 2008-2009. Data for this article is derived from participant observation research, and interviews. Participant observation research took place from November 2008 to February 2009 in one mobile home park in the city of McAllen located in the western part of the LRGV. During that time I attended park meetings, health screenings, and parties along with other social events. I also accompanied Winter Texans on outings (bird watching, dinners, church services) and 15 were accompanied as they traveled into Mexico for health care.

Semi-structured interviews were conducted with 50 Winter Texans, 15 US medical providers, and 15 Mexican medical providers. Interviewees were selected using stratified purposeful sampling. Inclusion criteria for Winter Texans was that they lived in a mobile home park. The group was then stratified by the following categories, between the ages of 55-65 and 66-85, new residents (lived for less than five years in the park) and old residents (lived in the park more than five years), and whether or not they used Mexican health care. Medical providers were included if they treated Winter Texans and were stratified by physicians, dentists, and pharmacists. Interviews were conducted at the locations selected by the participants.

Data was cleaned and imported into NVIVO 9 for analysis. Open-ended coding was used to identify themes (Bernard 2011) across the data set. The themes were then organized and linked together using memoing to develop a theoretical model (Dalstrom 2012).

Access to the park was obtained through contacting the park president and arranging a presentation during the weekly park meeting. Although I was only in my late $20 \mathrm{~s}$ during the time of the research, the migrants were largely receptive to me because I was from the Midwest and also because I was the same age as many of their grandchildren, making it easier to talk. As I spent more time in the parks, many of the residents saw me as a permanent fixture, and in a mock ceremony I was awarded my honorary Winter
Texan nametag. Because I was not 55, however, I was not able to live in the park, which restricted my access to activities that occurred in the evening.

\section{Seasonal Migration}

The practice of migrating to warmer climates for retirement is not new, nor is it limited to the US. It occurs throughout Canada (Counts and Counts 1996), between northern and southern Europe (Oliver and O'Reilly 2010; Boz 'ic' 2006; Warens and Williams 2006) and throughout the continental US. Called, international retirement migration, if it is international (Boz 'ic' 2006), retirement migration for permanent domestic migration (Warens and Williams 2006), and seasonal migration for temporary moves, these practices are characterized by the movement of people to a new community for the purpose of improving their lives.

For the most part, in both Europe and the US, seasonal migrants are "baby boomers" who are considered to be more healthy, wealthy, and less family oriented than their predecessors (Warens and Williams 2006), making international and domestic retirement migration possible. Since they are believed to be healthier and less tied to a particular place, many are open to the idea of permanently moving to retirement communities in Spain, Italy, Arizona, and Florida to name a few. These communities tend to consist of houses, apartments, and condos that enable independent living while restricting access based upon age. Many are built by large construction companies that advertise the possibility for seniors to "live in a blissful and perpetual state of mature adulthood" (McHugh 2000: 2) through providing an improved lifestyle. However, recent research by Fitzgerald (2000) illustrates that an increasing number of retirees in the US want to be close to family and home during their retirement years and do not want to live in permanent retirement communities in the south. For those people, seasonal migration is the perfect answer because it lets them leave during the cold winter months when their mobility is limited, spend time with their 'winter family,' and return in the summer to be with their biological families.

A common precursor to seasonal migration in North America is becoming an RVer earlier in life. According to Counts and Counts (1996) there are many types of RVers, ranging from full-timers (who live in their RV all year), snowbirds (who travel south in RV during the winters), serious part-timers (spend at least six months in their RV), and vacation RVers (212). While the practice can be traced 
back to the 1920s and 1930s the modern RV movement began in the 1950s when it gained a sense of respectability as RV clubs developed to support the practice. These clubs became ways for RVers around the country to meet, share ideas, destinations, and develop a robust sub-culture. As the demographics in the county began to change and more people with disposable income lived longer, RVing became a way for retirees to travel, have a sense of adventure, and meet new people at RV parks around the county (34-39). Within the LRGV, the practice followed a similar pattern as the number of RV parks grew and became informal locations for retirees to intermingle. By the 1960s, their popularity was entrenched in the LRGV as they evolved from a collection of concrete slabs with electrical hook-ups to established retirement communities.

\section{Promoting Fun, Sun, and Mexico to Midwesterners}

Every fall, as the leaves begin to change, retired Midwesterners begin packing up their RVs and cars to head south to the southeast Texas border. Over 150,000 strong, they gradually descend upon the LRGV, which stretches across Cameron, Hidalgo, Starr, and Willacy counties. While Winter Texans have been migrating to the LRGV since the 1920s, it was not until the late 1970s that they were considered an important research topic and a systematic study of their origins, spending habits, and activities began to be reported. "A Survey of Winter Visitors in the Lower Rio Grande Valley" (School of Business Administration 1976) sampled 1,505 households and found that most Winter Texans originated from Minnesota, Iowa and Illinois. Subsequent surveys found that over thirty years later the origin communities have remained virtually unchanged (Ghaddar and Simpson 2008).

It has been known for a long time that as people age they begin to orient themselves and make decisions to move based upon their social and experiential ties to a place (Oldakowski and Roseman 1986), which, can be established through friends and relatives living in that place (Gober and Zonn 1983). This phenomenon is particularly visible among the Winter Texan population who started traveling south almost a century ago. Early Midwestern migration began as a result of increased economic opportunities, as wealthy land developers began to recruit farmers from the Midwest through advertising cheap labor, land, and a rail system to take produce north. The campaign was very successful and by the early 1900s as some towns in the LRGV like McAllen went from 150 to 5,300 residents within ten years of being founded (Mittelstaedt 2013).
While railroads allowed for produce to leave the LRGV, they also facilitated travel via the Southern Pacific Railroad and Missouri Pacific to St. Louis and Chicago connecting family members and friends.

By the 1920s some businessmen in the LRGV wanted to compete with Florida for tourism dollars and began marketing the climate to northerners (Robinson 2006). The first national campaign was discussed in 1925 by the Valley Chamber of Commerce. For the venture, Brownsville, the largest city in the LRGV, provided 10,000 USD and organized a committee to raise an additional 25,000 USD. The money was used to create a booklet that was distributed in 1926 at agricultural conventions throughout the country. The committee also approached the Missouri Pacific Railroad who hired a newspaper man to conduct a local campaign to raise awareness of the tourism opportunities. At the same time, the Chicago based Gilllock Development Company produced a pamphlet called "Buried Treasure" to promote economic development in the area. The cover showed two people peering out of a snow-covered house that was contrasted to a scene of palm trees. The caption reads "Come south to the Lower Rio Grande Valley of Texas from the frozen north to where the sunshine spends the winter." (Robinson 2006: 213).

By the 1930s the advertising effort was believed to be largely successful as the LRGV had a "reputation for being a being a leading winter tourist resort area" (Mittelstaedt 2013). Nevertheless, it wasn't until the 1960s that another advertising innovation spurred the growth of tourism. In the late 1960s, Hank Stanley opened Fun-N-Sun RV Park for retirees, which offered more than just an electrical hookup and a concrete platform like the competitors. He believed that RV parks should be more of a community, blending healthy living, tourism, and entertainment. By 1970 his park had grown from 150 to 550 sites that were mainly occupied by "farmers from the Midwest. It became a place where people spend the winter," he said (Del Valle 2008). Fun-N-Sun quickly became a template for other parks in the area that advertised exercise programs, dances, live music, and in some cases church services. Moreover, the name Winter Texan was coined by the park minister, C.L. Boyle (Del Valle 2008). The McAllen Chamber of Commerce quickly latched onto the term starting a billboard campaign to promote its use. By the late 1970s, the name was firmly rooted when the University of Texas-Pan American began tracking their impact in the community (School of Business Administration 1976).

Over the years, LRGV has continued to target the retired population emphasizing the climate, friendly people, 
social activates, and proximity to Mexico. For example, in Highways Magazine, with a circulation of 50,000 readers there was advertisement with elderly people golfing, eating, sailing, and walking past the palm trees with the caption "Come spend the winter with the folks who are glad to see you...eat drink and be merry in Old Mexico... the lifestyle is laid back here in the friendly Rio Grande Valley" (Vincent 1993: 14).

In addition to advertising, word of mouth referrals have played and important role attracting new people to the LRGV. Conversations with Winter Texans about their decisions to visit the LRGV tend to sound like, "My parents used to live here," "I had friends down here and they told me to come" or "I was in Florida and I didn't like it, people told me about the Valley so I came here." One local businessman described it as such:

Word of mouth played a big part of getting Winter Texans here and they would invite friends to come down and when they began to stay as Winter Texans, they had more friends down here than they knew what to do with.

Elaborating on that sentiment, a pair of Winter Texans from Iowa said that that they had a conversation with another couple who had told them "how good it was" and that they had strongly urged them to visit. So they did and within one winter they bought an RV.

Winter Texans can also be very passionate about the LRGV and have on occasions taken it upon themselves to promote it to other people. For example, Vera, a Minnesota resident was concerned because her friends in St. Paul, MN were not able to get adequate information about wintering in Texas. So she and a few of her Winter Texans neighbors, took promotional materials from the McAllen Chamber of Commerce to the Minnesota State Fair, where they set up a booth to advertise the LRGV.

This perpetual migration between the Midwest and the LRGV ensures that new migrants have a pre-existing social support network before they travel and that close connections are maintained with the home community. In short, a continuous supply of retirees is maintained through self-selection, selective recruitment, and network recruitment (Longino 1994). Therefore it is inadequate to see seasonal migration as "movement between distinct environments" (Rouse 1992: 162) because of the strong connections that reside at both locations. Rather it is a "circuit" that links current and future retirees to both locations and is the template for community formation in the parks.

\section{From Midwesterner to Winter Texan: Moving into Ocean Valley}

Ocean Valley RV Park is like a lot of the mobile home parks built in the Fun-N-Sun model scattered throughout the LRGV, and the American southwest. Located on the outskirts of McAllen the park is enclosed by a five-foot chain-link fence that separates it from the neighboring park on one side and a small residential community on the other. A welcome sign greets new visitors along with a sign for people to check-in. The park is laid out in a gridlike fashion that separates the 427 lots into blocks that are organized into smaller communities.

Each block is named by the street that it is on and is led by a block captain. Block captains are elected leaders who are in charge of promoting social activities on the block, notifying next of kin in case of emergencies, and organizing the neighborhood watch program. While I was there, the block captains reported to the board of directors, who were elected by the entire park and are in charge of running the daily activities of the park. The Board met weekly in the Recreation Hall, located in the center of the park and all residents were expected to attend weekly meetings about the park's business. Most of the park's activities occurred within the Hall, which was large enough to hold 800 people.

Living in the park is restricted to those of age fifty-five and older, and although the park is in Texas, none of the residents are native Texans. Most of the residents only lived in the park for a few months during the winter, traveling back north during the months of March and April. In October, when they return south, the composition of the park changes from previous years as residents die or are not able to make the journey. Those who cannot make the journey back are commonly replaced by other Midwesterners who have familial connections and/ or friendships with people who already live in the park. Every year, as new residents enter the park, they are taken under the wing of older residents, some who have over twenty years experience living in the park. The bonds that newer residents share with established park families were particularly strong and form the template for the transfer of knowledge about the area. Under their guidance, new residents learn about park customs, life in the LRGV, and tourism in Mexico. The strong commitment that is shared between residents is epitomized by the common statement, "They are my second family." 
During their time at the park, residents lived in trailers, but spent little time there, electing instead to socialize in the communal areas with their neighbors. The center of social life was the Recreational Hall, located near the main entrance of the park. Every time I visited the Hall residents were playing games (usually cards or shuffle board), exercising, socializing, or preparing for large gatherings such as dances or the weekly park meetings. For instance, at the weekly park meetings held in the Hall, retirees had the opportunity to share announcements with fellow park residents and solicit volunteers for a variety of activities such as quilting, trips to Mexico, and intra-park competitions (horse shoes, scuffle board, etc.).

Life during the winter is structured around multiple social identities, the block, the park, and state residency. Each block had its own block captain and every week during the winter had a social function. Certain blocks also took on particular characteristics. For example Santa Rosa Street is known as the party block, because they celebrate everything. According to a resident they even had a "Christmas tree funeral, when the block's tree died and four men acted as pall-bearers carrying the tree down the street." Then afterwards everyone drank beer and celebrated. On another occasion, the block rented a keg of beer and carried the keg into the middle of the community pool, where there was a little sitting platform, so they could drink without "getting hot [leaving the pool]." Other blocks were known for being quiet, or for the social activities that people engage in.

Aside from block membership, there was a lot of pride associated with park membership. Long term residents tended to have high levels of personal satisfaction with their park and often compared themselves with others, "we are much nicer than the [blank] park," "unlike others we own our land so you can't get kicked out," or "you can walk down the street and talk to almost anybody." Park identity was further reinforced through nametags that residents wore both in and out of the park, which prominently displayed the park's name and location. Furthermore, intra-park competitions in bowling, cards, and singing allow residents to compete with people from other parks. Since parks in the area are also segregated along class and regional differences, intra-park competitions enabled residents to engage in both class and national/regional completions through seemingly benign activities. For instance, there were several parks in the area that catered almost exclusively to the upper middle class and were so expensive as to be prohibitive for residents of Ocean Valley. Residents of these upper class parks were ridiculed for being "exclusive," and for "not having a community spirit," because they paid people to do the park maintenance jobs instead of relying of volunteers. Other parks in the area have regional appeal attracting large numbers of people from one state in the US or province of Canada. However, away from the parks, Winter Texans saw themselves as having more of a collective identity and engaged in the same social activities (volunteering, bird watching, golf, shopping, etc.) regardless of their park identity

Integration and becoming part of the park community was emphasized within Ocean Valley, nevertheless, the primary responsibility falls upon the Welcoming Committee. One former committee member explained, that when new retirees arrived, they would "tell them about the activities" and "just welcome them leaving it open so they can ask us questions and we would answer whatever their concerns were." Then, "they would feel part of the park." To further support integration, older residents took newer ones under their wing acting as mentors, "showing them where to go," "fun places," and what "to avoid." Moreover, the mentors encouraged people to participate in the park activities as emphasized in the welcome packet:

All...residents are encouraged to contribute their energy and skills to park activities. This is an ideal way to become acquainted with many neighbors that are part of the "great group" that makes...[Ocean Valley] the best. ${ }^{2}$

In both cases, residents of the park prided themselves on being a community and welcoming new residents. Volunteers provided all necessary labor within the park. The residents ran the welcome desk, managed the annual dues, planned parties, and arranged trips, making a strong community vital to the functioning of the park. Most new residents found out about the park through friends and families since the park hasn't advertised in decades. In some cases, whole families of siblings live in the park and it is common for friends from the same hometown to move into Ocean Valley. There are a handful of rental properties that allow new residents to "see if they fit" before they buy into the park. Once integrated, they tend to return every year. Some of the "original" residents well into their 90s still come to the park if they are healthy enough and have relatives to drive them. In recent years, the amount of widows has grown as it has become more socially acceptable to be alone and as more children have encouraged their parents to "have fun and be with friends." However, illness is always present and it is a sad time when people are no longer physically able to make the journey. For the first few weeks of every fall, residents anxiously await to see who will be able to make it and who 
does not return. News of a person's deteriorating health spread quickly in the park, and if he/she needs to sell the lot where they park their RV, a retired real-estate agent in the park helps them do so. Along with the sadness of the loss there can also be a lot of excitement as new property goes on sale. Some lots are highly sought after because they are larger or on a popular block, so as soon as they go on sale residents will enter into a bidding war over them. Aside from the potential of having a larger lot, moving enables people to change their block which alters both their political representation (block captain) and social obligations (block parties). When the lots are not bought internally, they are sold to new people who represent the vitality of the park.

Just as important as socializing, is maintaining connections with their home community. According to Bjelde and Sanders (2009) seasonal migrants keep in touch with their family and friends through phones, email, home visits, inviting people to stay with them, and having children drive them to the park. While all those are present in Ocean Valley, residents also organized themselves around their state affiliations. For instance, it was common for individuals to talk about their home state and put signs on their RV that indicated what city or town they were from such as, "The Browns, East Troy, WI." In addition, groups of people from the same state organized social events for residents who lived in different parks. One particular event was the state dinner, where residents of a state such as Iowa got together. These dinners could be small consisting of one mobile home park, or large with all of the parks in the area invited. For some of the larger dinners, business from the home state, contributed gift cards and other items that were raffled off during the meal. In Ocean Valley, there was a state dinner for all the major states represented: Iowa, Illinois, Wisconsin, and Minnesota and residents were encouraged to sell tickets to people both in and out of the park. During the summer, when they were back home, residents were also tasked with getting businesses to donate to the dinner.

The connection to Ocean Valley does not end during the summer months when people return to the Midwest. For instance, those who leave frequently maintain contact with the permanent migrants who are tasked with taking care of the park maintenance during the summer months. Furthermore, during the summer, groups of residents will meet at state and national parks in the US and Canada to celebrate birthdays, anniversaries, and mourn deaths. Through these year-round activities, residents of Ocean Valley continually reinforce both their Midwestern identity and their strong social and community affiliation with the LRGV. This ensures that when they migrate south again, they will go back to the same park, continuing the transmigration circuit.

\section{Migration and the Impact on Health}

Appropriate and affordable medical care is a particular concern for the residents of the park. The average Winter Texan is 69.5 years old (Ghaddar and Simpson 2008), and many of those interviewed indicated that they were taking multiple prescriptions and required monitoring for a chronic condition (such as high cholesterol, blood pressure, diabetes). While most Winter Texans have health insurance (67.9 percent have Medicare A, 67.2 percent part $\mathrm{B}$, and 55.6 percent private health insurance) (Ghaddar and Simpson 2008), they still face gaps in coverage, high prices, and long waiting times at hospitals and clinics in the US. Some Winter Texans also mentioned they did not have access to appropriate medical coverage in the Midwest because they lived in rural areas and often had to drive hours to get to major medical centers. Moreover, some healthy living practices, such as exercise, are challenging during the winter months when seniors tend to be less mobile. Consequently, seasonal migration to the LRGV enables seniors to experience a wider range of health promoting activities, including access to the low cost health care in Mexico.

\section{Healthy Living the Park}

Living in the park impacts seniors' health by providing exercise options, health screenings, and access to the Mexican health care system. It also gives seniors access to a community and support network that has been linked to a higher quality of life (Koropeckyj-Cox 2002), and increased activity which has been linked to younger age, better self-rated health, and less functional limitations (Agahi, Ahacic, and Parker, 2006). In Ocean Valley there were daily exercise opportunities such as walking clubs, biking clubs, water aerobics, dancing, weight watchers toning and stretching classes. In addition, there is a small gym that is open seven days a week. The warm climate in the winter also enabled people to be outside more often and be overall more mobile than if they were living in the Midwest.

Exercise programs in the park counteracted the common barriers seniors have exercising in the Midwest: cost, transportation, lack of motivation, unfamiliarity with exercise personal, and lack of confidence (Wright and Hyner 2009). As one women mentioned, "at home I try to walk, but I don't do any of the other exercises. It 
is very difficult and hard to exercise by yourself." Some of the residents explained that the activities, "keep them busy," "happy," and feeling better than their other counterparts up north. Others went as far as to comment that "I wouldn't still be alive if I didn't come down here." However, as seniors age they are less able to participate and eventually they restrict themselves to less physical activities like playing cards, singing, or making quilts for poor Mexican children.

Aside from physical activities, living at the park provided access to medical care at lower prices than in the Midwest. At the Hall, local hospitals and medical clinics offered flu shots, blood pressure checks, stroke screenings, and wellness screenings that cost half what they would in the Midwest. Some of the residents even postponed tests in the Midwest, preferring the lower costs in the park. Frequently, when the results came back a week or so later, the health care organization sent a representative to give a presentation, explain the results and recommend follow-up care. These events were highly attended and are credited by the attendees for saving the lives of several of the residents through early detection. After the presentations, residents mingled with each other, discussing the results and offering anecdotal stories about the medications and treatments that they used or are using. Those who were still confused about their test results usually looked for retired medical professionals who lived in the park for additional information. For those identified as needing additional care, the nearest hospital was minutes away.

Sometimes, after receiving their results and attending the meeting, residents would come to the conclusion that they no longer needed a medication, either because they were cured or decided it was no longer effective. For example after one meeting, a woman sitting next to me handed me her medical results, smiling, and told me that her cholesterol was under control and she no longer needed Lipitor (a popular cholesterol lowering medication). Happy for her, I asked out loud what people do with all the extra medication. Her friend, Rita, a twenty-year veteran of the park explained that residents give the medication away or trade it for another that could be more effective. Recalling what she recently did after her medication was not working, Rita said:

People trade a lot of medication at the park ... the doctor is always prescribing for you, and I have to pay for it and I take it for a week or so and I get a bad reaction to it and I have to throw it out. Maybe it cost me $\$ 200$ and somebody here is taking the same thing, the same strength. What I used to do is put a note on the bulletin board [in the Hall] saying, "Anybody taking blank?" and put my phone number on it and they would call me and I would give it to them.

This enabled residents to mitigate some of the costs that their friends might incur purchasing the medication. It also became the template or basis for a medicine exchange. Through the exchange, some people entered into a pharmaceutical giving or trading cycle where they constantly shared, gave, or sampled their friend's pharmaceuticals. Coupled with lower costs, primary and preventative care, and a community support network living in the park provided access to health care that they would not necessarily have if they stayed in the Midwest. ${ }^{3}$

\section{Accessing Mexican Medical Care}

Living in the Ocean Valley also facilitated access to Mexico which offered a variety of cross-border medical services including pharmaceuticals, dental care, physician consultations, unapproved treatments, and surgeries (Dalstrom 2012). While there are many locations within the country for potential patients to receive care, the most popular medical destination for retirees in Ocean Valley was the Mexican border city of Nuevo Progreso, located about 45 minutes southeast of the park.

Access to the town is relatively simple, and seniors can either walk or drive across the Progreso-Nuevo Progreso International Bridge into the town. No identification is needed to walk into Mexico, and pedestrians are rarely stopped or searched by Mexican Customs or the Army. Nuevo Progreso has a thriving tourist district, which is the center of economic activity in the town. It consists of roughly five city blocks stretching south of the international border. Like many tourist districts in Mexico, Nuevo Progreso has restaurants, bars, liquor stores, and a plethora of street vendors selling jewelry, DVDs, and Mexican crafts, but it was the 72 dental clinics, 61 pharmacies, and 8 physicians offices that appealed most to many seniors.

The lower costs and easy access to Mexican medical care was particularly appealing. For example, according to the Winter Texan Market Survey, 51 percent of Winter Texans bought prescriptions, 36 percent dental care, and 6 percent visited a physician in Mexico (Ghaddar and Simpson 2008). Overall though, cost was the primary reason they used the Mexican health care system. For instance, some Winter Texans reported that they saved up to 70 percent on their dental care and pharmaceuticals and more than 50 percent on Lasik eye surgery and abdominal surgery (Dalstrom 2012). 
Aside from cost, accessing health care in Mexico enabled Winter Texans to bypass insurance regulations and reluctant primary care physicians. For example, seniors went to Mexican pharmacies they were able to purchase the medication that they wanted or needed without a prescription As a result, seniors had the ability to self-medicate. In Ocean Valley this meant that retirees frequently traded medications purchased in Mexico that they no longer needed or wanted and recommended prescription medications to their friends. Then, when they found a medication that they liked, they purchased up to a years supply in Mexico. As one retiree explained, "I know what I have, I know what I need, so why do I have to pay a doctor to tell me what I know? I can just get it in Mexico" Some even looked for surgical opportunities such as Arlene, a 70-year-old retiree from Iowa who was very displeased with her optometrist who repeatedly refused to give her Lasik eye surgery. Frustrated, she went to Mexico and shopped around until she found an optometrist who would perform the surgery.

Many people are very concerned about the quality of Mexican health care especially in terms of whether it is as good as care in the US. For those concerned about the quality, they described it as "haphazard," "dangerous," "not as advanced," and "risky." Their fears were not entirely unwarranted, and the FDA (2011), along with numerous doctors and dentists, have discouraged their use (Dalstrom 2012). However, for many seniors, the choice was not that easy and the dilemma, as one resident explained, is often between "some care and no care." The burden of making the decision about care in Mexico that could be dangerous, but desperately needed, falls onto the individual. Self-treatment can be particularly dangerous within the Winter Texan community because many believe that they should not tell their primary care doctor or dentist within the US because they are afraid that the doctor will dissuade them or that it will somehow impact their health insurance coverage.

Recommendations were particularly important to assuage concerns and new residents commonly listened to more seasoned veterans. Therefore while there are numerous dentists and pharmacists in Nuevo Progreso, residents only utilize a few of them. In effect, certain providers become park dentists and pharmacists. For example, four years ago, Jerry was suffering from a bunion and a hammertoe, which caused her considerable pain. She saw several doctors in the US about it and they all told her that she needed surgery. Unfortunately though, she was hesitant because her deductible of 2500 USD made the prospects of surgery very expensive. One day she was at the flea market where she met another Winter Texan who had a similar procedure. During the conversation, Jerry found out that in Mexico the procedure was 1000 USD less than in the US. The catch was that the surgery was not yet approved in the US (but was practiced in Europe), and Jerry would have to bring her own medicine and foot brace to the hospital. However, because she was told that the doctor was good, she proceeded with the surgery.

Using patient recommendations does not always work out well, as in the case of Paul, who selected a dentist for a root canal based upon a friend's suggestion. During the procedure, the dentist only gave him an Ibuprofen for the pain and used a pair of pliers to remove a few teeth until he vomited and passed out. When he returned to the US he had several cracked teeth and a root canal that had to be redone, costing him an additional 5,000 USD. However Paul's story was a rarity in the park and now no one from the park uses that dentist anymore. More often, residents talked about the good deal they received in Mexico and how they had "waited all year to go to Mexico" because they could not afford the care in the US. Medical decisions that have positive outcomes are lauded as examples of the benefits of consumer choice and resistance to the US medical establishment. They are also used as the basis to connect health care in the Midwest to Texas. Proud of their medical prowess, Winter Texans spend the summer months telling their family and friends about the savings and benefits of Mexico. In response, people will ask Winter Texans to purchase medication on their behalf and it is not uncommon to see Winter Texans purchasing Mexican medication for their entire family or all their close friends in the Midwest. In addition, Winter Texans will invite their friends and family to visit them at the park so they can easily cross into Mexico for dental care and surgeries.

This created a very interesting situation where Winter Texans and their family members were diagnosed in the US and delayed treatment until the winter when they were able to access more affordable care in Mexico. For instance, John, a Winter Texan from Iowa was told by his dentist in July that he needed two root canals. Distressed by the high cost of the procedure, he waited until October until he could see the park's Mexican dentists, because as said, "Why should I pay more for the same care." The practice of waiting extends past dental care with some of the interviewees postponing knee, Lasik, and foot surgery. When asked why they waited most people indicated that it really was not that hard of a choice. Either their health 
insurance did not cover the procedure or the deductible was just too high. Since the surgery was not urgent, they would have to save up to afford it either way, so why not get a "better deal" in Mexico.

Therefore, for many Winter Texans and their families, health care is not something that is situated in the Midwest, but is part of, and intimately related to the circuit that connects Mexico, the LRGV, and the Midwest. Just as people move in a predictable pattern, so does medication, patients, and health care information. As new residents are integrated into the park, they are also exposed to and learn about Mexican health care. Older residents will frequently take them into Mexico to show them how the process works and to assure them that it is safe. For those integrated into the system, medical decisions are conceptualized spatially, in terms of the location that can provide them the care that they need, and temporally, depending on when they need care and what they can wait for. When framed within context of Mol's (2008), discussion of the "logic of choice," a neoliberal notion that the commodification of health care services and choice produce better patients and health outcomes (which many Winter Texans believe in), it becomes easier to understand why using healthcare in the LRGV is so popular. Access and usage of health care in the parks empowers retirees to choose the type and delivery of their health care. Moreover through bypassing their primary care providers in the Midwest, Winter Texans shift the burden of medical decision making onto themselves, allowing them to make decisions the same way that they make migration decisions.

Through the dual benefit of having access to Mexican health care and health care within the park, retirees are able in some cases to increase the availability of health care services and decrease the overall cost. Coupled with exercise programs, social activities, and living arrangements that cater to older people, Winter Texans have the possibility of living, happier, healthier lives. As one resident stated, "If I was not here, I would be dead."

\section{CONCLUSION}

Retiring is not what it used to be. For some it marks the opportunity to travel, move, and have adventures-the antithesis of the aging in place model. To meet the growing demand for this lifestyle during retirement, a growing amount of branded retirement developments have emerged to cater to specific retiree desires (Fitzgerald 2000; McHugh 2000). However, not all people want to move to fulltime community and instead desire part-time living arrangements. For those individuals, seasonal migration is one solution to meet the desire for living within a community of seniors and maintaining their home.

Seasonal migration from the Midwest to the LRGV began early in the twentieth century through the development of a phenomenon akin to the transmigration circuit. The circuit developed over the past century as Midwesterners came to the area to work, then visit, and eventually spend the winter. During that time the LRGV actively advertised to them, eventually developing seasonal RV parks that offered social activates, warm weather, and a strong community. Retirees who decided to winter in these parks rarely did so alone, frequently following friends and family. Through migrating with friends and family retirees, they are able to mitigate the often stressful and lonely experience of moving to a retirement community. Moreover, many indicated that through migrating, their quality of life increased as they were able to be social, exercise, and be outside during the winter months.

Living in the park also impacted health in some unique ways. First of all, many hospital and clinics in the LRGV provide discount health screenings and services in the parks on a monthly basis. Residents are encouraged to take advantage of these opportunities and also to assist newer residents in accessing medical care in the area. Sometimes, that care is in the US, but in other circumstances it means using Mexican health care. Regardless of where the care is received, Winter Texans have more access to health services that generally cost less than they would in the Midwest. Moreover, through accessing health care in the parks, Mexico, and the Midwest, they are able to fashion and utilize an entirely different health care system than their peers in the Midwest.

With all the opportunities available, Winter Texans have found a successful way to mitigate the problem of aging in place, feeling separated from their home community, and needing support by seasonally traveling south. When they move to their retirement communities they take their friends and family with them creating a support network that stretches across the county. New residents often are already connected with the park either through social connections or because they are from the same origin community. Once there, they form a tight knit community that becomes the basis for a variety of health seeking and social activities which improve the overall aging experience. 


\section{Acknowledgements}

This project was funded by the National Science Foundation Doctorial Dissertation Improvement Grant, "Motivations for Medical Migration in the United States/ Mexico Borderlands" (BCS-0848478).

\section{EndNotes}

1 There are other regions that send retirees to the Midwest, however because of space limitations this paper will only address the Midwest.

2 The citation for this pamphlet is not given to protect the amenity of the park.

3 The FDA (FDA 2011). discourages patients from using prescription medication without medical supervision because of the potential health risks.

\section{REFERENCES}

Agahi, Neda, Kozma Ahacic, and Marti O. Parker 2006 Continuity of Leisure Participation From Middle Age to Old Age. Journals of Gerontology Series B: Psychological Sciences \& Social Sciences 61(6):340- 346.

Bartling, Hugh

2006 Tourism as Everyday Life: An Inquiry into The Villages, Florida. Tourism Geographics 8(4):380-402.

Bekhet, Abir and Jaclene Zauszniewski

2011 Creating a Therapeutic Milieu in Retirement Communities. Issues in Mental Health Nursing 32:327334.

Bernard, H. Russell

2011 Research Methods in Anthropology: Qualitative and Quantitative Approaches. New York: AltaMira Press.

Bjelde, Kristine E, and Gregory F Sanders

2009 Snowbird Intergenerational Family Relationships. Activities, Adaptation, and Aging 33:81-95.

Bookman, Ann

2008 Innovative Models of Aging In Place:

Transforming our Communities for an Aging

Population. Community, Work and Family 11(4): 419438.

Boz`ic, Sas`a

2006 The Achievement and Potential of International

Retirement Migration Research: The Need for

Disciplinary Exchange. Journal of Ethnic and

Migration Studies 32(8): 1415-1427.

Chui, Kenneth, Steven Cohen, and Elena Naumova

2011 Snowbirds and Infection-new Phenomena in
Pneumonia and Influenza Hospitalization from Winter Migration of Older Adults: A Spatiotemporal Analysis. BMC Public Health 11(444): 1-12.

Counts, Dorothy and David Counts

1996 Over the Hill: An Ethnography of RVing Seniors in North America. Peterborough, Ontario: Broadview Press.

Dalstrom, Matthew

2012 Winter Texans and the Re-Creation of the American Medical Experience in Mexico. Medical Anthropology 31: 162-177.

Del Valle, Fernando

2008 Fun-N-Sun Proved Revolutionary and Gave

Birth to the Term 'Winter Texan.' Valley Morning Star (Harlingen, TX). December 29: Newspaper Source, EBSCOhost, accessed August 28, 2012.

FDA

2011 Buying Medicine from Outside the U.S. is Risky Business (a). F.a.D. Administration, ed: U.S. Department of Health and Human Services.

Fitzgerald, Kate

2000 New Housing Options Abound. Advertising Age 71(29): 8.

Fry, Christine

1979 Structural Conditions Affecting Community Formation Among the Aged: Two Examples from Arizona. Anthropological Quarterly, Special Issue: The Ethnography of Old Age 52:7-17.

Ghaddar, Suad, and Penny Simpson

2008 Winter Texan Market Survey. University of Texas-Pan American, Edinburg: The Valley Market and Tourism Research Center.

Gober, P. C., and L.E. Zonn

1983 Kin and Elderly Amenity Migration. Gerontologist 23:288-294.

Kao, Hseuh-Fen S., Shirely S. Travis, and Gayle J. Acton 2004 Relocation to a Long Term Care Facility: Working with Patients and Families. Journal of Psychosocial Nursing 42(3):10-6.

Koropeckyj-Cox, Tanya

2002 Beyond Parental Status: Psychological Well-being in Middle and Old Age. Journal of Marriage and Family 64:957-971.

Longino Jr., Charles

1994 From Sunbelt to Sunspots. American Demographics 16(11), 22. 
McHugh, Kevin

2000 The 'Ageless Self'? Emplacement of Identities in Sun Belt Retirement Communities. Journal of Aging Studies 14(1): 103-126.

Mchugh, Kevin and Robert Mings

1994 Seasonal Migration and Health Care. Journal of Aging and Health 6(1): 111-132.

Mittelstaedt, Gerard

2013 Outline History of McAllen Texas and Surrounding Area. South Texas Boat Website. http:// www.stexboat.com/Texas/McAllen_brief_hist.htm, accessed January 1, 2013.

Mol, Annemarie

2008 The Logic of Care: Health and the Problem of Patient Choice. New York: Routledge.

Oldakowski, R. K., and C.C. Roseman

1986 The Development of Migrant Expectations: Changes Throughout the Lifecourse. Journal of Gerontology 41:290-295.

Oliver, Caroline, and Karen O'Reiley

2010 A Bourdieusian Analysis of Class and Migration: Habitus and the Individualizing Process." Sociology 44(1): 49-66.

Robinson, Robin

2006 Promoting Valley Tourism in the 1920s: A Case of Competition and Ambivalence. In Further Studies in Rio Grande Valley History. vol 7. M. Kearney, A. Knopp, and A. Zavaleta, eds. Pps: 202-220. Brownsville: The University of Texas at Brownsville.

Rossen, Eileen, $\mathrm{K}$.

2007 Assessing Older Persons Readiness to Move to Independent Congregate Living. Clinical Nurse Specialist 22(7):292-296.

\section{Rouse, Roger}

1992 Mexican Migration and the Social Space of Postmodernism. In The Anthropology of Gobalization: A Reader. J.X. Inda and R. Rosaldo, eds. Pp. 157-171. Malden, MA: Blackwell Publishers.

School of Business Administration

1976 A Survey of Winter Visitors in the Lower Rio Grande Valley. Edinburg, TX: University of Texas-Pan American.

Sullivan, Deborah

1985 The Ties that Bind: Differentials Between Seasonal and Permanent Migrants to Retirement Communities.
Research on Aging 7:235-250.

Valle, Fernando Del

2008 Fun-N-Sun proved Revolutionary - and Gave Birth to the Term 'Winter Texan'. In The Monitor. McAllen, TX.

Van Den Hoonaard, Deborah Kestin

2002 Life on the Margins of a Florida Retirement Community: The Experience of Snowbirds,

Newcomers, and Widowed Persons. Research on Aging 24(1):50.

Vincent, Vern

1993 Advertising for New Winter Texans: What is the Payoff? Edinberg: University of Texas Pan American.

Warens, Anthony, and Allan Williams

2006 Older Migrants in Europe: A New Focus for Migration Studies. Journal of Ethnic and Migration Studies 32(8): 1257-1281.

Werner, Carrie A.

2011 The Older Population: 2010 . US Census Bureau. http:/ / www.census.gov/prod/cen2010/briefs/ c2010br-09.pdf (accessed May 5, 2012).

Wright, Tim. J., and Gerald Hyner

2009 Principal Barriers to Health Promotion Program Participation by Older Adults. American Journal of Health Studies 24(1), 215-222. 